ODP Science Services

ODP Technical Note 35

\title{
Ocean Drilling Program Safety MANAGement Policies ${ }^{1,2}$
}

\author{
ODP Science Services ${ }^{3}$
}

\section{ABSTRACT \\ University Commitment to Safety and Health}

Texas A\&M University (TAMU) is committed to providing its employees, students, and visitors a safe environment in which to work, study, and play. Safety is the business and responsibility of every campus citizen and can be better achieved through proper engineering, education, training, protective equipment, and enforcement of safety rules. Each student and employee is responsible for understanding and practicing appropriate safety procedures for his or her own protection and to protect others. All Deans, Directors, Department Heads, Chairpersons, and Supervisors must take an active role in the University's safety program by initiating preventive measures to control hazards associated with activities under their direction.

TAMU's commitment to safety and health is extended to all members of the Ocean Drilling Program (ODP) science operations, including staff located at Headquarters, satellite repositories, and aboard the JOIDES Resolution. This manual is an introduction to ODP's Safety Management Policies for research facilities aboard the JOIDES Resolution operated by ODP/TAMU.

\section{INTRODUCTION}

This manual is intended to provide structure and guidance to the supervisors, staff, and visitors working in the research facilities aboard the JOIDES Resolution in complying with Texas A\&M University (TAMU) and international marine safety programs. The section called "Impor-
${ }^{1}$ ODP Science Services, 2006. Ocean Drilling Program safety management policies. ODP Tech. Note, 35 [Online]. Available from World Wide Web: $<$ http://www-odp.tamu.edu/ publications/tnotes/tn35/

INDEX.HTM>. [Cited YYYY-MM-DD]

${ }^{2}$ See Disclaimer, p. 30.

${ }^{3}$ Ocean Drilling Program, Texas A\&M University, 1000 Discovery Drive, College Station TX 77845-9547, USA. 
tant Definitions" provides definitions of important terms used throughout this manual. The remaining sections describe the following four main safety programs with which ODP is required to comply:

1. Laboratory Security Program: This program requires that public access to TAMU laboratories be controlled and shipments of equipment and materials to and from the laboratory be monitored. See "Laboratory Security Plan" for the compliance plan for this program.

2. Precursor Chemicals and Laboratory Apparatus Program: This program is based on a 1995 Memorandum of Understanding (MOU) between the Texas Department of Public Safety and the Texas Higher Educational Coordinating Board (THECB). Specifically, the MOU establishes procedures for maintaining controlled substances, controlled substance analogs, chemical precursors, and chemical laboratory apparatus used in educational or research activities at institutions of higher education. See "Precursor Chemicals and Laboratory Apparatus" for the compliance plan for this program.

3. International Safety Management (ISM) Code: The ISM Code establishes procedures to ensure safety at sea, prevent human injury or loss of life, and avoid damage to the environment, in particular to the marine environment and to property. See "International Safety Management Code" for the compliance plan for this program.

4. TAMU's Hazard Communication Program (HazCom). This program describes how TAMU complies with the Texas Hazard Communication Act (THCA). See "TAMU Hazard Communication Program" for the compliance plan for this program.

The Laboratory Safety and Hazard Communication Compliance Manual (B. Mills, unpubl. document, 2002 [N1]) should supplement the information in this manual. In addition, emergency assistance contact numbers and instructions are available in Figure F1.

\section{Maintenance of This Manual}

This manual will be reviewed, updated, and republished (as needed) each June by the Supervisor of Technical Support. The policies stated in this manual will supercede all other policies as of its publication and revision dates.

\section{Other ODP Safety Documents}

Specific safety-related topics are addressed in the following ODP documents. These documents are available from ODP/TAMU and on the JOIDES Resolution. This list will be updated periodically, as appropriate.

1. Laboratory Safety and Hazard Communication Compliance Manual (B. Mills, unpubl. doc, 2002 [N1]) provides detailed guidance for scientific and technical staff on board JOIDES Resolution in complying with the TAMU HazCom. It also covers the basics of laboratory safety and management of hazardous chemicals.

2. Hydrogen Sulfide Drilling Contingency Plan, ODP Technical Note, 33 (Mills et al., in press) provides guidance in recognizing, prepar-
F1. Emergency assistance contact numbers and information.

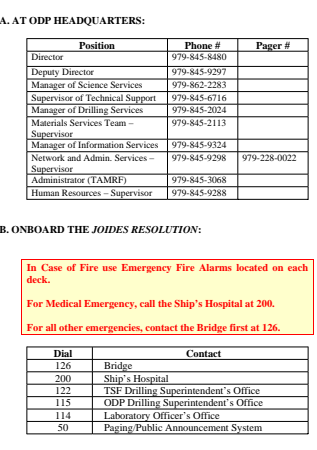


ing for, and mitigating potentially dangerous hydrogen sulfide $\left(\mathrm{H}_{2} \mathrm{~S}\right)$ situations during drilling and coring operations.

3. Introduction to Shipboard Organic Geochemistry on the JOIDES Resolution, ODP Technical Note, 30 (Pimmel and Claypool, 2001) describes hydrocarbon monitoring procedures.

4. Guidelines for Site Survey and Safety, ODP Technical Note, 32, addresses fundamental issues of site selection and operational procedures to minimize drilling hazards and risks of accident or pollution.

5. The Crisis Management Plan provides a framework for response to and ultimate recovery from an emergency or crisis that threatens personnel and/or property both at ODP/TAMU Headquarters and on board the JOIDES Resolution.

\section{IMPORTANT DEFINITIONS}

- EHSD: TAMU Environmental Health and Safety Department.

- Employee: Any person (including students) who is on the payroll of TAMU or a Texas A\&M University System (TAMUS) agency and who may be exposed to hazardous chemicals in the workplace under normal working conditions or a foreseeable emergency. Employees (e.g., secretaries and office workers) whose employment does not include routine exposure to hazardous chemicals are not covered by the THCA. THCA regulations also do not apply to students who are not employed by TAMU or a TAMUS agency.

- Laboratory Officer: Supervisor of scientific work areas and technical staff aboard the JOIDES Resolution.

- ODP: Ocean Drilling Program.

- Precursor Chemicals: The THECB and the Texas Department of Public Safety (DPS) developed an MOU intended to prevent diversion of equipment and chemicals from academic laboratories to the production of illicit drugs.

- TAMU: Texas A\&M University.

- TAMU HazCom Program: Describes the procedures whereby the University complies with the THCA.

- Research Laboratory: A facility that engages only in research or quality control operations. Chemical specialty product manufacturing laboratories, full-scale pilot plant operation laboratories that produce products for sale, and service laboratories are not research laboratories. Chemical storerooms (unless accessible only through a research laboratory) and teaching laboratories are NOT research laboratories.

- Visiting Scientists: Scientists (excluding ODP Staff Scientists) that participate on a cruise on board the JOIDES Resolution.

- Science Party: Includes TAMU employees, participating scientists, observers, and contractors sailing aboard the JOIDES Resolution.

- Technically Qualified Individual: An individual with a professional education and background working in the research or medical fields, such as a physician, a registered nurse, or a person holding a college bachelor's degree in science. 
- Workplace: All research facilities aboard the JOIDES Resolution operated by TAMU.

- Work Area: Room, laboratory, decks, or defined space in a workplace where hazardous chemicals are present, produced, used, or stored and where TAMU employees or visiting scientists are present.

\section{LABORATORY SECURITY PLAN}

"Appendix A" describes the "University Research Facilities and Laboratories Security" plan devised by TAMU on 25 October 2001. This plan has been adapted by ODP to reflect the JOIDES Resolution environment both in port and at sea.

\section{Security in Port}

\section{Personnel Access Control}

Only individuals on the approved boarding list are allowed to board the JOIDES Resolution in port without an escort. Employees or subcontractors working for either the ship's owner or ODP are automatically approved and will be issued a JOIDES Resolution photo identification (ID) card. This ID must be worn at all times when working on board or on the dock and must be presented to the gangway watch when boarding the ship during personal time. Therefore, the ID should be carried at all times when the individual leaves the ship. The JOIDES Resolution photo ID must be turned in when the individual leaves the employment of the ship's owner or ODP.

Scientists, consultants, and observers that are leaving or boarding the ship for the next scientific cruise or have worked aboard the JOIDES Resolution in the past and are familiar with the ship's safety concerns are issued a color-coded visitor's card. A photo ID (passport or driver's license) is necessary to verify identification before a visitor's card can be issued. The card must be worn at all times when working on board or on the dock and must be presented to the gangway watch when boarding the ship during personal time. Therefore, the visitor's card should be carried at all times when the individual leaves the ship. Visitor's cards must be turned in when the visitor leaves the ship for the last time.

The visitor's card color changes each leg and is available from the ship's Yeoperson. In addition, port officials, shipping agents, and service representatives can be issued a visitor's card by ship officers and department heads, ODP Operations Manager, Laboratory Officer, and Staff Scientists.

All other individuals boarding as part of a tour group must wear a guest tag and be escorted at all times by the tour guide while aboard the ship. Guest tags are issued when the individual boards the ship and must be returned when they leave.

\section{Gangway Watch}

In unsecured ports, a gangway watch will be posted $24 \mathrm{hr}$ per day. The gangway watch is charged with ensuring that all individuals boarding the ship are on the approved boarding list or are wearing a JOIDES Resolution photo ID, a valid visitor card, or a guest tag. 
While in port, an ODP official will be available (on board or by phone contact) to assist with identification of visitors.

\title{
Hazardous Material Delivery and Access
}

Before any hazardous material is allowed on board the JOIDES Resolution, the Laboratory Officer will determine that the material can be used safely and the Captain will give his approval to load the material on board. All bulk chemical storage cabinets will be locked while the ship is in port.

\section{Security at Sea}

At sea, the JOIDES Resolution is isolated from public access, with the exception of piracy. Policies regarding piracy are covered in the ship's safety and policy procedures. Ship personnel are not required to wear their JOIDES Resolution photo ID or visitor's tag while at sea.

\section{General Shipboard Safety Policies and Procedures}

\begin{abstract}
Alarms
Personnel not directly involved in dealing with an emergency are to report to their assigned stations immediately upon hearing an alarm. This facilitates assignment of additional help or directing abandon-ship procedures. Depending on the severity of an emergency, the Captain may call upon any or all hands aboard for assistance; therefore, everyone must be ready to respond to any order the Captain or ship's officers may issue in a drill or real emergency.
\end{abstract}

\section{Types of Alarms}

There are different emergency alarms to signify unsafe conditions aboard ship:

- General emergencies: For a general emergency, such as a fire or collision, the general alarm and ship's whistle sound for at least $10 \mathrm{~s}$ and instructions describing the type of emergency and location are given over the public address system.

- Abandon ship: For abandon-ship circumstances, six short blasts followed by one long blast are given on the alarm and whistle. One short blast means to lower boats; two short blasts means to stop lowering boats. Accompanying commands and instructions to abandon ship are given over the public address system.

- Man overboard: If a person falls overboard, an alarm is given by hailing "Man Overboard" and notifying the mate on duty. Three long blasts on the whistle may be given.

- Return to safe conditions: When an emergency is over, the "All Clear" signal for dismissal is given by three short blasts of the whistle and general alarm.

\section{Alcohol}

Use of alcoholic beverages or controlled substances is forbidden. In 1988 the U.S. Government enacted the Drug-Free Workplace Act, which contains a requirement for federal contractors and grant recipients to maintain drug-free workplaces by adhering to certain requirements. 
The act specifically prohibits the "unlawful manufacture, distribution, dispensation, possession, or use of a controlled substance" in the workplace. Workplace is defined as all areas of the vessel. Failure to comply with this law may result in loss of government funding.

ODP and Transocean prohibit alcohol and drugs aboard the scientific research vessel JOIDES Resolution, not only to comply with the relevant laws and regulations, but also to reduce the risk of injuries to persons and property. Accordingly, ODP relies upon the integrity, professional attitude, and good judgment of all cruise participants to refrain from engaging in these types of activities.

\section{Compassionate Emergencies}

It is the policy of the ODP not to interrupt or alter the course of a cruise for the purpose of evacuating an ODP employee or a cruise participant in the event of a personal emergency on shore. Personal emergencies include but are not limited to a death in the family or the serious illness of a family member. Exceptions to this policy may be made at the discretion of the ODP/TAMU Director or Deputy Director. An exception would be based in part on the location of the ship, availability of resources for evacuation, and the nature of the emergency.

\section{Derrick}

Personnel are prohibited from going aloft in the derrick because of safety issues.

\section{Drills}

The scientific work of the JOIDES Resolution takes her to areas where immediate assistance is unavailable. Thus, it is necessary to rely upon the knowledge and experience of the ship's crew to avoid potentially dangerous situations. This is done in a systematic way developed through the practice of weekly drills. These drills are required by law, and the ship takes pride in the serious manner in which they are organized and executed. Fire drills, man overboard drills, and abandon ship drills are held at least once weekly; attendance is mandatory. Helicopter emergency drills are held less frequently. Procedures and details connected with these drills are explained at the first drill, which is held a few hours out of port.

\section{Hard Hats}

Hard hats and safety glasses must be worn by all ODP and Transocean personnel when outside on catwalks, rig floor, or aft decks (on the way to the helipad or underway geophysics lab, for example).

\section{Firearms}

Firearms or other weapons cannot be transported or possessed on board ship.

\section{Fires}

If you should discover a fire or a similar dangerous situation, do not try to combat it! The first and most important action to take is to notify the bridge immediately (see Fig. F1 for instructions) and stand by to aid 
or point out the area involved to the Emergency Squad as they arrive. If in your judgment you would be able to help by using an extinguisher on a fire at its inception, you may do so only after you notify the bridge. After the Emergency Squad has taken control, go to your assigned emergency station.

\section{Halon Fire Extinguisher System}

The shipboard computer facility is protected by a Halon fire extinguisher system, which is located in the Koomey room on the upper 'tween deck. This system protects the computer machine room, system manager's office, and computer user's area. Only the Captain may authorize manual activation of the Halon system in the event of a fire. A loud alarm sounds, and protected areas must be evacuated immediately and all doors tightly closed. Halon is nontoxic but it must be contained within the air-tight protected area to be effective. As in all emergency situations, the bridge must be notified first.

\section{Lifeboats}

The JOIDES Resolution is equipped with four motor-propelled, selfcontained, totally enclosed lifeboats, each with a 56-person capacity. The boats contain oxygen breathing systems to be used when operating in a fire area. There is also a complete exterior water-spray system to prevent buildup of excessive interior temperatures. Lifeboats are located above the bridge deck, two each on port and starboard. They are launched and boarded from the fo'c'sle deck. In addition to the lifeboats, the ship has inflatable life rafts.

\section{Lifeboat Assignments}

Lifeboat assignment and emergency signals are posted in passageways and personnel stations. This information must be thoroughly and carefully read; the Chief Mate or Captain can answer any questions.

\section{Life Jackets}

Life jackets are worn during every boat drill by all persons. Regulation-type jackets are kept aboard for all personnel. They are stored in each cabin and near each lifeboat. Immersion suits are also stored in each cabin and in the labstack.

\section{Rig Floor}

In the interest of preventing accidents it is requested that, while on site, all persons not directly connected with drilling operations stay off the rig floor. For those who are not familiar with the machinery and its operation or who do not take proper precaution, crossing the rig floor while pipe operations are in progress can be extremely hazardous. The driller and his team are operating equipment that handles loads of over 300 tons under dynamic conditions, and that activity is unforgiving of error. The driller is responsible for the safety of everyone on the rig floor; a lapse in concentration on the driller's part could easily result in a serious or fatal accident to a visitor or crew member. It could also cause a "wreck" with disastrous consequences to the equipment, drill string, or even the voyage.

The following guidelines must be observed on the rig floor: 
1. Wear a hard hat and safety glasses outside the deck house and lab stack areas, and wear safety shoes on the rig floor and around machinery or moving loads.

2. Avoid the drill floor during pipe handling operations unless you have specific business there, and then walk around behind the drawworks as an alternative to crossing the drill floor. Don't visit with or otherwise distract the driller while he is operating machinery.

3. Don't ever walk between the iron roughneck or the dual elevator system and the centerwell, and don't walk on the pipe-racker catwalk unless you have a real need to do so and are fully aware of the current operational situation.

4. Be constantly alert for men working aloft in the derrick and for crane loads being swung overhead, and DON'T stand underneath!

5. Don't use the rig floor as a route of convenience to the underway geophysics or logging winch areas.

\section{Smoking}

Smoking is permitted only in non-dangerous areas and is never allowed where "No Smoking" signs are posted. Smoking is permitted in the living quarters only where signs are posted stating it is a "designated smoking area."

\section{PRECURSOR CHEMICALS AND LABORATORY APPARATUS}

\section{Introduction to Memorandum of Understanding}

The 1995 MOU between the Texas DPS and the THECB establishes procedures for maintaining controlled substances, controlled substance analogs, chemical precursors, and chemical laboratory apparatus used in educational or research activities at institutions of higher education. This document also defines the requirements and procedures necessary for TAMU's compliance with the MOU. The full text of the MOU is available from the TAMU EHSD (979-845-2132).

The objective of the MOU is to heighten awareness regarding the potential problem of the diversion of laboratory chemicals and apparatus to illegal drug operations. The list includes many common pieces of laboratory equipment in addition to possible precursors for the manufacture of illicit drugs. Table AT1 provides a list of the controlled items including precursor chemicals and related laboratory apparatus and glassware whose purchase, use, transfer, and disposal must be monitored. The complete procedures and requirements that are necessary for TAMU to comply with the MOU are listed in "Appendix B."

On campus, the Control of Precursor Chemicals and Laboratory Equipment Implementation Plan is posted in areas where controlled items are ordered, received, used, or stored (Fig. AF1). If there are any questions concerning these documents, please contact the Chemical and Biological Safety Officer in the EHSD (979-845-2132) or contact the Director of Security or University Police (979-845-8058) for assistance with security and police matters. 
ODP's Control Procedures

The MOU does not apply to the JOIDES Resolution, as the ship operates outside the jurisdiction of the Texas DPS. Nevertheless, the chemicals and equipment listed in Table AT1 must be controlled while in the state of Texas. When these equipment and chemicals are purchased for the ship, it is the responsibility of the Marine Logistics Coordinator to maintain a record of all purchases of controlled chemicals and equipment and to ensure that they are kept in a locked storage room until shipped from ODP to the JOIDES Resolution.

For equipment returned from the ship for storage or surplus, it is the responsibility of the shipping Laboratory Officer to notify the Supervisor of Technical Support of the pending shipment. Once the equipment has arrived at TAMU, the Supervisor of Technical Support ensures that the equipment is kept in a locked storage room and is available to only authorized personnel.

\section{INTERNATIONAL SAFETY MANAGEMENT CODE \\ Introduction to the ISM Code}

The ISM Code provides an international standard for the safe management and operation of ships and for pollution prevention. The ISM Code requires that the ship's owner establish safety objectives that ensure safety at sea, prevention of human injury or loss of life, and avoidance of damage to the environment, in particular to the marine environment and to property. To view the full text of the ISM Code, see www.imo.org/Safety/mainframe.asp?topic_id=478.

Application of the ISM Code should support and encourage the development of a safety culture in shipping. An appropriate organization of management, ashore and on board, is needed to ensure adequate standards of safety. A systematic approach to management by those responsible for management of ships therefore requires the implementation of a Safety Management System (SMS) with the following objectives:

1. Provide for safe practices in ship operation and a safe working environment.

2. Establish safeguards against all identified risks.

3. Continuously improve safety management skills of personnel ashore and aboard ships, including preparing for emergencies related both to safety and environmental protection.

4. Comply with mandatory rules and regulations.

5. Consider applicable codes, guidelines, and standards recommended by marine safety organizations, the government of the state under which the ship is flagged (or an authorized organization acting on their behalf), the classification societies, and the maritime industry organizations.

6. Provide adequate resources and shore-based support to enable the designated person or persons to carry out their functions.

Specifically, the SMS must establish procedures for the following: 
1. Definition and documentation of the responsibility and interrelation of all personnel who manage, perform, and verify work relating to and affecting safety and pollution prevention.

2. Assurance that the ship is manned with qualified, certified, and medically fit seafarers in accordance with national and international requirements.

3. Familiarization of new personnel and personnel transferred to new assignments with safety- and protection-related issues of the environment and with their duties. Instructions, which must be provided prior to sailing, should be identified, documented, and disseminated.

4. Assurance that all employees have an adequate understanding of relevant rules, regulations, codes, and guidelines.

5. Identification of any training that may be required in support of the SMS and assurance that such training is provided for all personnel concerned and that their training is maintained.

6. Identification, description, and response to potential emergency shipboard situations.

7. Development of a program for drills and exercises to prepare for emergency actions.

8. Provision for measures ensuring that the ship owner's organization can respond at any time to hazards, accidents, and emergency situations involving its ships.

9. Assurance that nonconformities, accidents, and hazardous situations are reported to the ship owner and investigated and analyzed with the objective of improving safety and pollution prevention.

10. Development of procedures for implementing corrective action.

11. Assurance that the ship is maintained in conformity with the provisions of the relevant rules and regulations and with any additional requirements established by the ship's owner. This assurance can be provided by conducting inspections at appropriate intervals, reporting any nonconformity with its possible cause (if known), reporting the corrective action taken, and keeping records of the above activities.

12. Identification of equipment and technical systems the sudden operational failure of which may result in a hazardous situation. The SMS should provide for specific measures aimed at promoting the reliability of such equipment or systems. These measures should include the regular testing of standby arrangements and equipment or technical systems that are not in continuous use.

13. Development of procedures to maintain and control all documents and data that are relevant to the SMS. These procedures must ensure that valid documents are available at all relevant locations, changes to documents are reviewed and approved by authorized personnel, and obsolete documents are promptly removed.

Upon implementation of the SMS, the government of the state under which the ship is flagged (or an authorized organization acting on their behalf) must verify that the SMS complies with the requirements as stipulated in the ISM Code, as well as verify compliance with mandatory rules and regulations. Upon verification of compliance with the require- 
ments of the ISM Code, a Document of Compliance (DOC) will be issued to the ship's owner and a Safety Management Certificate (SMC) will be issued to the ship.

\section{ODP's Obligations to ISM Code Compliance}

It is the responsibility of the ship's owner and their staff to ensure that the JOIDES Resolution is in compliance with the ISM Code. Because TAMU (through ODP) operates and staffs research facilities aboard the JOIDES Resolution, ODP has elected to assist the ship's owners and the crew in their efforts to ensure compliance.

\section{TAMU HAZARD COMMUNICATION PROGRAM}

The TAMU HazCom describes how TAMU complies with THCA. To view the full text of the TCHA, see http://tlo2.tlc.state.tx.us/statutes/ statutes.html. A copy of the most recent version of the TAMU HazCom program is provided in "Appendix C." The full text can be obtained from ESHD.

Implementation and compliance with TAMU HazCom aboard the JOIDES Resolution requires ODP to complete the following:

1. Develop a written procedure that describes the method of implementing the TAMU HazCom program in the workplace (ship: Workplace Implementation Plan) and designated work areas in the workplace (laboratories; Work Areas Implementation Plan). The Workplace Implementation Plan will be completed by the designated department official, not by each Principal Investigator or Supervisor. Copies of the Workplace and Work Areas Implementation Plan are kept in the Laboratory Officer's Office aboard the JOIDES Resolution and in the Human Resources Office at ODP Headquarters in College Station, Texas.

2. Compile and maintain an annual workplace chemical inventory (WPCI) of all the chemicals stored on board the JOIDES Resolution.

3. Maintain a file of current Material Safety Data Sheets (MSDS) for all chemicals purchased and stored on the JOIDES Resolution and ensure proper labeling of chemicals to conform to the MSDS identification.

4. Ensure that the employees (and science party) have received proper training before working with or in an area containing hazardous chemicals.

Note: There are instances in which granting agencies require grantees to have a Chemical Hygiene Plan (as specified by the Occupational Safety and Health Administration [OSHA] Laboratory Standard) in place. The THCA does not include a laboratory standard component. However, the completed Chemical Safety Manual fulfills the requirements of the OSHA Laboratory Standard.

For a complete description of the JOIDES Resolution Workplace and Work Areas Implementation Plans, refer to the Laboratory Safety and Hazard Communication Compliance Manual (Section 1) (B. Mills, unpubl. doc- 
ODP SCIENCE SERVICES

ODP SAfety MANAgement Policies

ument, 2002 [N1]). Section 1 of this manual also addresses issues related to workplace and work areas inventories, MSDS and labeling of chemicals, and training of the science party. 


\section{REFERENCES}

Graber, K.K., 2006. Guidelines for site survey and safety. ODP Tech. Note, 32 [Online]. Available from World Wide Web: <http://www-odp.tamu.edu/publications/ tnotes/tn32/INDEX.HTM>.

Mills, W.G., Malone, M.J., and Graber, K.K., 2006. Hydrogen sulfide drilling contingency plan. ODP Tech. Note, 33 [Online]. Available from World Wide Web: <http:// www-odp.tamu.edu/publications/tnotes/tn33/INDEX.HTM>.

Pimmel, A., and Claypool, G., 2001. Introduction to shipboard organic geochemistry on the JOIDES Resolution. ODP Tech. Note, 30 [Online]. Available from World Wide Web: <http://www-odp.tamu.edu/publications/tnotes/tn30/INDEX.HTM>. [Cited 2002-09-01] 
APPENDIX A

\section{University Research Facilities and Laboratories Security}

Richard F. Ewing

Vice President for Research

October 25, 2001

MEMORANDUM

TO: Texas A\&M University Faculty and Laboratory Staff

FROM: Dr. Richard E. Ewing

SUBJECT: University Research Facilities and Laboratories Security

In light of the recent acts of terrorism in our nation, it is necessary that the Texas A\&M research community review the security of Texas $A \& M ' s$ research facilities and laboratories. While the University, and the Nation, consider possible long-term security and safety measures, we believe this is an appropriate time to examine, reinforce, and/or increase existing security measures across our campus. The actions that need to be taken at this time result from an assessment by the Office of the Vice President for Research, which is under my purview; the Environmental Health and Safety Department, which reports to Vice President for Finance and Controller William B. Krumm; and the University Police Department, which reports to Vice President for Administration Charles A. Sippial, JR Research Facilities.

With that in mind, attached is a suggested Laboratory Security Plan to aid in your review of security procedures in your colleges' facilities and/or laboratories. These actions should be implemented immediately, as appropriate, in all University facilities and laboratories where hazardous chemicals, radioactive materials, biological agents or toxins are located, as well as at sites at which laboratory animal or human participants research is conducted.

Again, this is an intermediate security plan while, in conjunction with the Environmental Health and Safety Department and the University Police Department, we are in the process of developing long-term security and safety measures. We are also in the process of developing broader information to provide to you on security and safety concerns, which we hope to send to you in the near future

On a related note, it is increasingly likely that faculty and staff will be contacted or visited by members of the media, law enforcement, or concerned citizens regarding hazardous materials and/or security. You are not obligated to respond to any of these individuals or groups. Contacts and visits by law enforcement members or groups should be referred to Robert E. Wiatt, Director of Security and University Police (845-8058, or bobwiatt@tamu.edu), contacts by the media should be referred to Cynthia J. Lawson, Executive Director of University Relations (862-2302, or cil@univrel.tamu.edu); and contacts by regulators and/ or inspectors should be referred to Christopher M. Meyer, Director, Environmental Health \& Safety Department (845-2132, or c-m-meyer@tamu.edu). If you have general questions, you may con- 
tact Michael W. Buckley, Director of Compliance and Administration, in my office, at 845-8585, or mwbuckley@tamu.edu.

\section{University Research Facilities and Laboratories Security Plan}

Research facilities and laboratories where hazardous chemicals, radioactive materials, biological agents, or toxins are present must be kept secure at all times. At a minimum, this involves limiting access to the facility and laboratory and locking the door when no facility and laboratory personnel are present.

Facilities and laboratories need to take the following steps to prevent unauthorized entry into a facility or laboratory and, in turn, prevent unauthorized removal of hazardous materials from a facility or laboratory:

- Approach any visitors that appear to be wandering in facility or laboratory areas and ask if you can help direct them.

- Report suspicious or unexplained behavior to the University Police Department (emergency $=9-911$; nonemergency $=845-2345$ ). Lock all equipment (e.g., freezers, cabinets, incubators, and scintillation counters) that contain hazardous materials and are located in hallways or areas outside of facilities or laboratories.

- Keep facility and laboratory doors closed at all times.

- Lock facility and laboratory doors when no one is present.

- Put emergency contact signs on facility and laboratory doors, including a 24-hr contact number.

- Program speed dial of emergency contacts (e.g., 9-911, facility or laboratory director, etc.) on the phones in the facility or laboratory, if possible.

\section{Facility and Laboratory Security and Emergency Response}

- Facility and laboratory directors should review security procedures regularly to ensure that they are adequate for current conditions and consistent with other facility- and laboratory-wide policies and procedures.

- Facility and laboratory supervisors should ensure that all facility and laboratory personnel and visitors understand security requirements and are trained and equipped to follow established procedures.

- Access to areas where hazardous materials are used and stored should be controlled. The facility or laboratory and animal housing areas should be locked at all times. Only workers or students (required to perform a job) should be allowed in a facility, laboratory, or housing areas, and workers should be allowed only in areas and at hours required to perform their particular job.

- Access during nonroutine work hours should be limited to authorized personnel.

- Access for routine cleaning, maintenance, and repairs should be limited to hours when facility and laboratory employees are present.

- Freezers, refrigerators, cabinets, and other containers where stocks of biological agents, hazardous chemicals, or radioactive materials 
are stored should be locked when they are not in direct view of workers (e.g., when located in unattended storage areas).

- All new employees should be known to facility and laboratory personnel. Depending on the hazardous materials involved and the type of work being done, a background check and/or security clearance may be appropriate before new employees are assigned to the facility and laboratory areas. Guests must be escorted or cleared for entry using the same procedures as for regular workers.

- It is best to use the "buddy system" when using hazardous materials in a facility or laboratory. However, if it is necessary to work in the facility or laboratory alone during nonroutine hours, let someone know where you will be and how long you expect to be in the facility or laboratory. Arrange for someone to check on you at least hourly.

- Know what materials are being brought into the facility and laboratory areas. All packages should be screened before being brought into the facility or laboratory area. If a suspicious or unexpected package is delivered to the facility or laboratory, do not open it. Contact the University Police Department (emergency = 9-911; nonemergency $=845-2345$ ).

- Know what materials are being removed from the facility and laboratory areas. Hazardous materials must be packaged and labeled in conformance with all applicable local, federal, and international shipping regulations. The recipient should be known to the sender, and the sender should make an effort to ensure that materials are shipped to a facility or laboratory equipped to handle those materials safely. Contaminated or possibly contaminated materials should be decontaminated before they leave the facility or laboratory areas.

- Control of access to facility and laboratory areas can make an emergency response more difficult. This must be considered when emergency plans are developed. Police, fire, and other emergency responders should be informed as to the types of hazardous materials in use in the facility or laboratory areas and special access control devices that are in use (e.g., card key, etc.).

- Facility and laboratory emergency planning should be coordinated with facility- and laboratory-wide plans. Bomb threats, severe weather, power outages, and other natural (or unnatural) disasters should be considered when developing facility and laboratory emergency plans.

- Facility and laboratory directors, in cooperation with the University Police Department, should have procedures in place for reporting incidents such as unauthorized persons in the building, missing chemicals or other hazardous materials, and unusual or threatening phone calls. 


\section{APPENDIX B \\ Precursor Chemicals and Laboratory Apparatus Implementation Plan}

An MOU between the DPS and the THECB places recordkeeping and control responsibilities on institutions, including TAMU. The MOU applies to the chemicals, laboratory glassware, equipment, and controlled substance analogs listed in Table AT1.

The following definitions and procedures are necessary for TAMU to comply with the MOU:

\section{Responsible Party}

Responsible parties include any person who uses or has access to or control of the listed items, including investigators, laboratory personnel, instructors, laboratory storeroom personnel, purchasing agents, and surplus property personnel.

\section{Purchase Order Records}

Controlled items listed on purchase orders should be marked with an asterisk, highlighted, or identified in some similar manner so they are readily distinguishable from all other items appearing on the purchase order. Purchase records are to be maintained according to State and Federal requirements and are subject to DPS audit.

\section{Transfer of Property}

Controlled items (including surplus property) may not be sold, furnished, or transferred to a person or entity not holding a DPS permit or waiver, unless the recipient is specifically exempted by law or rule. Every sale, furnishing or transferring of a controlled item leaving the immediate campus (where the specific controlled item is stored and inventoried) should be reported (by the 15th day of the next month) to the DPS on a Nar-22 Form. EHSD personnel will assist the TAMU Surplus Property and Inventory Department in compliance with the MOU.

\section{Security}

Report to the TAMU Police Department (UPD) promptly upon discovery of a readily unacceptable discrepancy, pilferage or theft of a controlled item. UPD is responsible for forwarding the report to DPS.

The Director of Security and University Police has primary responsibility for all matters associated with security and law enforcement on the TAMU campus.

Security procedures are as follows:

- Maintain locked storage for controlled precursor chemicals and controlled substance analogs. Strictly limit access to these chemicals. Use records should be maintained.

- Limit access to storerooms containing listed items to authorized personnel. Lock storage areas when unattended.

- All doors and windows into any rooms in which controlled items are used or stored must be locked when authorized personnel are not present.
AT1. List of controlled items. 
ODP SCIENCE SERVICES

ODP SAfety Management Policies

Notification and Awareness

Departments and units affected by the MOU should post in prominent and strategic location(s), notices to inform personnel of the MOU and of the steps necessary for compliance.

Encourage personnel to be alert and attentive to the disappearance of controlled items and to report such losses as appropriate.

\section{Assistance from the Texas Department of Public Safety}

Upon request, the DPS will provide technical advice to the institution and will assist UPD in investigating losses, etc. covered by the MOU. 


\section{APPENDIX C \\ Texas A\&M University Hazard Communication Program}

The Texas Hazard Communication Act (THCA), Revised 1993, Chapter 502 of the Health and Safety Code (HSC), requires public employers to provide information to employees regarding hazardous chemicals they may be exposed to in the workplace. The Public Employer Community Right-to-Know Act, Chapter 506 of the Health and Safety Code, and Texas Administrative Code (TAC), Title 25 Chapter 295, requires public employers to make information regarding hazardous chemicals accessible to local fire departments, local emergency planning committees, and, through the Texas Department of Health (TDH), the general public.

The TAMU HazCom Program is administered through the EHSD with responsibility for compliance delegated throughout administrative channels to every supervisor. The TAMU HazCom Program applies to all TAMU and TAMUS employees at the Main Campus (College Station), Riverside Campus (Bryan), and other designated University facilities. Student employees that have occupational exposure to hazardous chemicals are covered by this program.

TAMU, through the TAMU HazCom Program, will comply with the THCA by providing training, appropriate personal protective equipment, and information regarding hazardous chemicals. In addition, written plans that describe how the TAMU HazCom Program will be implemented will be maintained within each workplace.

\section{Program Exemptions and Exceptions HSC 502.004; 506.005}

The provisions of this program do not apply to chemicals in the following categories:

- Hazardous waste regulated under the Federal Resource Conservation and Recovery Act;

- Tobacco or tobacco products;

- Wood or wood products;

- Any article that is formed to a specific shape or design during manufacture, that has end-use functions dependent in whole or in part of its shape or design during end use, and that does not release or otherwise result in exposure to a hazardous chemical under normal conditions of use (e.g., tires, PVC piping);

- Food, drugs, cosmetics, or alcoholic beverages in a retail food sale establishment that are packaged for sale to consumers;

- Food, drugs, or cosmetics intended for personal consumption by an employee while in the workplace;

- Any consumer product or hazardous substance if the product is used in the workplace in the same manner as normal consumer use and if the use results in a duration and frequency of exposure that is not greater than exposures experienced by consumers;

- Any drug, as defined in the Federal Food, Drug, and Cosmetic Act;

- Radioactive waste; 
- A hazardous chemical in a sealed and labeled package that is received and subsequently sold or transferred in that package if:

- Seal and label remain intact while in the workplace;

- Chemical does not remain in the workplace more than five working days;

- Personnel training requirements are met; and

- Chemical is not an extremely hazardous substance at or above the threshold planning quantity or 500 pounds, whichever is less.

\section{Research Laboratory Exemptions}

Chemicals in a research laboratory are exempt from secondary labeling requirements and inventory requirements if:

- Laboratory is under the direct supervision or guidance of a technically qualified individual.

- Labels on primary containers of chemicals are not removed or defaced.

- Personnel training requirements are fulfilled.

- MSDS access requirements are satisfied.

- Laboratory is not used primarily to produce hazardous chemicals in bulk for commercial purposes.

Note: Labels for small containers, such as test tubes or vials, may be attached to the rack or container in which they are held.

\section{Duties and Responsibilities}

The Unit Head will assure implementation and compliance with the HazCom Program within their units as follows:

- Develop a written procedure that describes the method of implementing the TAMU HazCom Program within the Unit (Complete Attachment 2).

- Report any incident requiring outside medical assistance to the Director of EHSD.

- Designate work areas within each workplace (see definitions for work area).

- Post official "Notice to Employees" (Fig. AF1) at locations in each work area.

- Provide to the Director of EHSD by 1 November of each year the following:

- Annual Work Area Chemical Inventory (WACI) for each work area other than a research laboratory;

- WACI updates to the Director of EHSD, whenever a new chemical or additional quantity above normal restocking amounts of chemical is purchased;

- Annual notice of training completion (e.g., memo); and

- Names and telephone numbers of emergency contacts.

- Maintain training records for a minimum of 5 years.

- Assure that MSDSs on hazardous chemicals purchased are avail-

AF1. Notice To Employees.

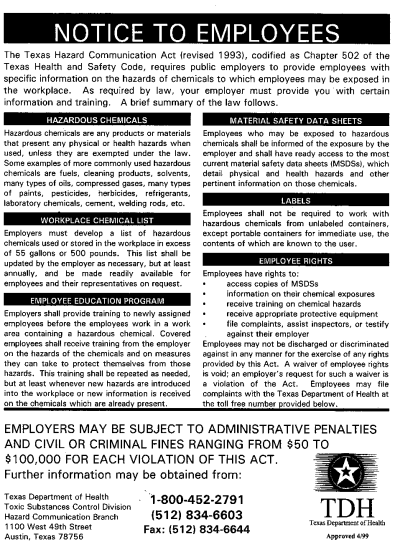
able, as required. 
- Provide employees with appropriate personal protective equipment and ensure the equipment fits the individual.

- Inform employees of any non-routine chemical exposure.

- Provide to the Director of EHSD, the name, campus address, e-mail address and phone number of the person with primary responsibility for HazCom coordination and compliance within the Unit.

The TAMU Director of EHSD administers and coordinates the HazCom Program for TAMU and designated University facilities. Duties of the Director include:

- Assign designated Workplaces at TAMU (College Station) and the Riverside Campus (Bryan).

- Assist Units with the implementation of, and compliance with this Program.

- Maintain liaison with the TDH (1-800-452-2791) as follows:

- Submit required annual Texas Tier Two report and fee to the Commissioner of Health by March 1 of the following year and

- Report orally or in writing, within $48 \mathrm{hr}$, the occurrence of a chemical accident that results in one or more fatalities or the hospitalization of five or more employees (this is to include circumstances of the accident, the number of fatalities, and the extent of injuries) HSC 502.0.

- Compile, maintain, and provide designated WPCI lists.

- Maintain the WPCI lists for 30 years.

- Provide a copy of the annual Texas Tier Two report to the Local Emergency Planning Committee and to the local fire department(s).

- Provide the names and telephone numbers of emergency contacts to the local fire department(s), and provide WPCI lists and MSDSs upon request.

- Allow for inspections by the local fire department.

Supervisors will ensure that the requirements of the TAMU HazCom Program and Unit Implementation Plan are fulfilled within their work areas. Their duties include the following:

- Ensure that all employees have received appropriate training before working with or in an area containing hazardous chemicals.

- Provide to the Unit Head all HazCom training records.

- Conduct and maintain the work area inventory list, as appropriate.

- Inform employees regarding the location of the work area inventory and procedures for accessing MSDSs and obtaining workplace chemical inventory lists.

- Inform the Unit Head whenever a new chemical or additional quantity above normal restocking amounts of chemical is purchased. (Not required for chemicals in research laboratories.)

Employees will fulfill the following requirements:

- Attend training.

- Use prudent practices and good judgment when using hazardous chemicals or hazardous procedures. 
- Notify other individuals who might be affected by the chemicals they use.

Note: Personnel who work with hazardous materials are expected to assume reasonable responsibility for the safety and health of themselves, others around them, and the environment.

Construction, repair, and maintenance contractors will comply with Texas and Federal Hazard Communication Acts and the TAMU HazCom Program regarding hazardous or nuisance materials used during projects within TAMU facilities and property as follows:

- Contractor will provide to the TAMU Project Coordinator a list of any hazardous or nuisance materials to be used on the project and will provide appropriate hazard information including MSDSs.

- Contractor will provide prior notification of intended use of hazardous or nuisance materials to the TAMU Project Coordinator, the EHSD, and the Unit Head of any affected TAMU workplace.

- TAMU Project Coordinator will provide to the EHSD pertinent information including MSDS for the chemicals involved.

- Unit Head will ensure that individuals in the affected workplace be provided information on the hazards of the chemicals, measures that they can take to protect themselves from those hazards, and access to MSDS.

\section{Nonroutine Exposure HSC 502.017(b)}

\section{Planned or Accidental Releases}

Party(ies) responsible for the release of hazardous or nuisance materials will notify all individuals in the affected area, the Unit Head, and the EHSD. The responsible party(ies) will also provide to the EHSD appropriate precautionary information, including MSDSs for the chemicals involved. The Unit Head will ensure that individuals in the affected area are provided information on the hazards of the chemicals, measures that they can take to protect themselves from those hazards, and access to MSDSs. Planned releases are not a substitute for proper waste disposal.

\section{Employee Notice and Rights of Employees HSC 502.017}

An official TDH "Notice to Employees" (Fig. AF1) will be posted at the location(s) within each workplace where notices are normally posted. EHSD will ensure that TAMU employees who may be exposed to hazardous chemicals (including products with which they do not work directly) are informed of the exposure and are provided access to the pertinent workplace chemical lists and MSDSs for those hazardous chemicals.

An employee shall not be disciplined, harassed, or discriminated against by an employer for filing complaints, assisting inspectors of the $\mathrm{TDH}$, participating in proceedings related to the THCA, or exercising any rights under the THCA. Employees cannot waive their rights provided by the THCA. 


\section{Chemical Safety Information and Training HSC 502.009 and 502.017(b)}

Employee education and training are essential components of the TAMU HazCom Program. Appropriate training will be provided to employees who use or handle hazardous chemicals as part of their normal work assignments. Training of a new or newly assigned employee will be given before the employee works with or handles hazardous chemical. Employees will receive additional training when the potential for exposure to hazardous chemicals in the employee's work area increases significantly or when the employer receives new and significant information concerning the hazards of a chemical in the employee's work area.

Training topics will include the following:

- Interpreting MSDSs and labels and the relationship between the two methods of hazard communication;

- Location of MSDSs and methods for obtaining MSDSs;

- Hazards associated with applicable categories of hazardous chemicals (e.g., flammable, corrosive, toxic, and reactive) including acute and chronic effects;

- Methods for identifying specific chemicals within each chemical hazard group (e.g., DOT labels, NFPA 704 system, chemical container labels);

- Identity and location of hazardous chemicals the employee will handle;

- Safe handling procedures, including proper storage and separation of incompatibles;

- Location, selection, use, and care of appropriate protective clothing and equipment to minimize exposure to hazardous chemicals;

- First aid treatment to be used with respect to the hazardous chemicals the employee will handle; and

- Instructions on spill cleanup procedures and proper disposal of hazardous chemicals.

\section{Lab Personnel/Students}

All personnel who work in laboratories and laboratory support facilities will receive the appropriate training. Students enrolled in laboratory courses will receive appropriate safety information and instruction if classwork involves hazardous chemicals; the instructor or class supervisor will provide this training.

\section{Training Records}

Each Unit will maintain, for at least 5 years, a record of each employee training session, including:

- Date of training;

- Attendance roster;

- Specific topics covered; and

- Names of the instructor(s). 
Documentation of HazCom training should also be placed in the employee's personnel file.

\section{Notification of Training Completion}

Units will provide annual written notice of training completion to the Director of EHSD stating that the required training for all Unit employees has been completed. This may be accomplished by a letter or memo.

\section{Material Safety Data Sheets HSC 502.006}

MSDSs are legal documents that provide hazard information on chemicals or chemical products produced or distributed in the United States. Federal and State laws require employers to provide employees access to MSDSs on hazardous chemicals or chemical products in the work environment. Each Unit will implement the following procedures:

- Maintain a file of current MSDSs for all hazardous chemicals purchased. The file may be electronic or printed and must be readily available, on request, for review by employees at their workplace. It is recommended that MSDSs be maintained within each work area (e.g., laboratory, shop) for those hazardous chemicals being used;

- Provide a copy of MSDSs to the Director of EHSD upon request.

- Submit a request within 30 days to any manufacturer who fails to supply a current MSDS with a hazardous chemical that was purchased;

A copy of an MSDS may also be obtained through the EHSD by calling 845-2132 or from ehsd-online.tamu.edu.

\section{Hazardous Chemical Inventory HSC 502.005}

\section{WACI (Excluding Research Laboratories)}

Each work area (e.g., teaching laboratory, chemical stock room, paint shop, art room, print center; but not research laboratories. See NOTE, below) will maintain an inventory list of all hazardous chemicals or chemical products present in the work area, regardless of quantity. The hazardous chemicals or products will be listed using the same name found on the label and MSDS. The WACI will include the following information, as appropriate:

- Name and telephone number of the person responsible for the work area and the name and signature of the person responsible for compiling the inventory;

- Unit name;

- Location of the hazardous chemicals (building and room);

- Chemical name or the common name of a product and its hazardous ingredients;

- CAS number;

- Container type; 
- Hazard associated with the chemical; and

- Quantity of product in pounds.

The supervisor of each work area will update and provide the inventory to the Unit Head annually, upon request, and when necessary. A WACI will be updated when a new chemical or additional quantity above normal restocking amounts of chemical is purchased. The Unit Head will provide the inventories to the Director of EHSD by 1 November each year and as necessary. The Unit will maintain a copy of each WACI for the current year and these will be readily accessible to employees.

The Director of the EHSD will use the WACIs to compile a WPCI. The WPCI includes only those hazardous chemicals in a designated workplace that are equal to or greater than the "workplace reporting threshold." If a designated WPCI-HSC 502.006 workplace is occupied by more than one Unit, a single WPCI will be compiled by combining WACIs for all Units within the workplace. The EHSD employee responsible for compiling the WPCI will sign and date it. The WPCI will remain on file at the EHSD for 30 years. A new WPCI for each designated workplace will be compiled by 31 December each year, or as needed. TAMU employees may obtain a copy of the WPCI from the EHSD, upon request.

\section{Tier Two Report-HSC 295.182(d); 506.006}

The Director of EHSD will compile a Texas Tier Two Report for TAMU Main Campus, Riverside Campus, and other designated University facilities. A separate report will be completed for each facility. The Texas Tier Two Report includes all hazardous chemicals and chemical products exceeding 10,000 $\mathrm{lb}$ and all extremely hazardous substances exceeding $500 \mathrm{lb}$ or the Threshold Planning Quantity, whichever is less. (A list of Extremely Hazardous Substances and the Threshold Planning Quantities are available through the EHSD Web homepage). The report will be submitted by 1 March each year, for the preceding calendar year, to the TDH with the appropriate filing fees. A copy of the Tier Two Report will remain on file at the EHSD until the following year's report is filed with the TDH. A copy of each Texas Tier Two Report is sent to the Local Emergency Planning Committee, the College Station Fire Department, and the Bryan Fire Department. The Tier Two Report will be revised and reported to TDH and local agencies, as appropriate.

\section{Container Labels HSC 502.007}

Containers of hazardous chemicals will be properly labeled as follows.

- Labels on primary containers must:

- Identify the material as it is on the MSDS;

- Include appropriate hazard warnings (an appropriate hazard warning includes the key word(s) of the chemical hazard such as, poison, flammable, corrosive, carcinogen, etc.; and

- Include the manufacturer's name and address.

- Labels on an existing container of a hazardous chemical may not be removed or defaced unless they are illegible, inaccurate, or do 
not conform to the OSHA Hazard Communication Standard or other labeling requirement. If a primary container label is removed or missing, the container must be relabeled with at least the information above.

- Labels on secondary containers of non-research laboratory chemicals will include the chemical identity, as it appears on the MSDS, and appropriate hazard warnings

- Complete labels are not required on portable container(s) intended for the immediate (within a work shift) use by the employee who performs the transfer. However, the contents should be readily identifiable.

\section{Definitions}

\section{Chemical Name}

The scientific designation of a chemical in accordance with the nomenclature system developed by the International Union of Pure and Applied Chemistry (IUPAC) of the Chemical Abstracts Service (CAS) rules of nomenclature or a name that clearly identifies the chemical for the purpose of conducting a hazard evaluation.

\section{Common Name}

A designation of identification, such as a code name, code number, trade name, or generic name, used to identify a chemical other than by its chemical name.

\section{Employee}

A person who is on the payroll of TAMU and who may be or may have been exposed to hazardous chemicals in the person's workplace under normal operating conditions or foreseeable emergencies.

\section{Expose/Exposure}

An employee is subjected to a hazardous chemical in the course of employment through any route of entry, including inhalation, ingestion, skin contact, or absorption. The term includes potential, possible, or accidental exposure under normal conditions of use or in a reasonably foreseeable emergency.

\section{Extremely Hazardous Substance}

Any substance as defined in EPCRA, Section 302, or listed by the United Sates Environmental Protection Agency in 40 CFR Part 355. The list of Extremely Hazardous Substances and Threshold Reporting Quantities can be accessed through the EHSD Web homepage (ehsdonline.tamu.edu).

\section{Hazardous Chemical}

Any element, compound, or mixture of elements or compounds that is a physical or health hazard. Relatively innocuous materials such as $\mathrm{NaCl}$, sugars, enzymes, and so on, are exempt. A hazard determination may be made by employers who choose not to rely on the evaluations made by their suppliers if there are relevant qualitative or quantitative differences. A hazard determination shall involve best professional judgment; factors such as quantity, concentration, physical properties (i.e., volatility) and use may be considered. 
ODP SCIENCE SERVICES

HazCom

Hazard Communication

\section{Health Hazard}

Includes chemicals that are carcinogens, toxic, or highly toxic agents, reproductive toxins, irritants, corrosives, sensitizers, hepatotoxins, nephrotoxins, neurotoxins, agents which act on the hemopoietic system, and agents which damage the lungs, skin, eyes, or mucous membranes.

HSC

Texas Health and Safety Code.

\section{Laboratory}

Any research, analytical, or clinical facility equipped for experimentation, observation, or practice in a science or for testing and analysis.

Name

Chemical identity on the container label, the MSDS, and inventory list.

\section{Personal Protective Equipment}

Includes clothing or devices intended to prevent exposure to hazardous chemicals (e.g., respirator, gloves, lab coat).

\section{Physical Hazard}

A material for which there is scientifically valid evidence that it is a combustible liquid, explosive, flammable, compressed gas, organic peroxide, oxidizer, pyrophoric, unstable (reactive), or water reactive.

\section{Primary Container}

The container in which the chemical arrives from the manufacturer.

\section{Readily Available}

Access during an individual's work shift.

\section{Research Laboratory}

Facility equipped for scientific investigation or experimentation aimed at the discovery and interpretation of facts, revision of accepted theories or laws in the light of new facts, or practical application of new or revised theories or laws. Note: For the purposes of the Texas Hazard Communication, this does not include teaching laboratories or chemical stock rooms.

\section{$T D H$}

Texas Department of Health.

\section{Texas Tier Two Report}

The report submitted annually to the TDH that reports quantities of hazardous chemicals per the Texas Tier Two Report from TDH.

\section{Unit}

A department, service, or other distinct administrative organization.

\section{Work Area}

A room, defined space, utility structure, or emergency response site within a workplace where hazardous chemicals are present, produced, used, or stored and where employees are present. 
Workplace

An establishment at one geographical location containing one or more work areas. A single building or a complex of buildings in close proximity with similar work activities can be designated as a workplace. TAMU workplaces are designated by the Director of Environmental Health and Safety.

\section{Workplace Chemical Inventory}

The list of hazardous chemicals in a designated workplace.

\section{Workplace Reporting Threshold}

The quantity (at any time during the year) of a hazardous chemical exceeds $55 \mathrm{gal} / 500 \mathrm{lb}$ or the Threshold Planning Quantity (TPQ) in pounds, or $500 \mathrm{lb}$, whichever is less, for those chemicals on the Extremely Hazardous Substance List. 


\section{NOTE*}

N1. Mills, B., unpubl. document. Laboratory Safety and Hazard Communication Compliance Manual. 


\section{PUBLISHER'S NOTES}

Material in this publication may be copied without restraint for library, abstract service, educational, or personal research purposes; however, this source should be appropriately acknowledged.

ODP Science Services, 2006. Ocean Drilling Program safety management policies. ODP Tech. Note, 35 [Online]. Available from World Wide Web: <http://www-odp.tamu.edu/publications/tnotes/tn35/INDEX.HTM>. [Cited YYYY-MM-DD]

Distribution: Electronic copies of this publication may be obtained from the ODP Publications homepage on the World Wide Web at www-odp.tamu.edu/publications.

This publication was prepared by the Ocean Drilling Program, Texas A\&M University, as an account of work performed under the international Ocean Drilling Program, which is managed by Joint Oceanographic Institutions, Inc., under contract with the National Science Foundation. Funding for the program is provided by the following agencies:

Australia/Canada/Chinese Taipei/Korea Consortium for Ocean Drilling: Department of Primary Industries and Energy (Australia), Natural Resources Canada, National Taiwan University in Taipei, and Korean Institute for Geology, Mining, and Minerals

European Science Foundation Consortium for Ocean Drilling (Belgium, Denmark, Finland, Iceland, Ireland, Italy, The Netherlands, Norway, Portugal, Spain, Sweden, and Switzerland)

Federal Republic of Germany, Bundesanstalt fur Geowissenschaften und Rohstoffe

France, Institut National des Sciences de l'Univers-Centre National de la Recherche Scientifique (INSUCNRS)

Japan, University of Tokyo, Ocean Research Institute

People's Republic of China, Marine High-Technology Bureau of the State Science and Technology Commission of the People's Republic of China

United Kingdom, Natural Environment Research Council

United States, National Science Foundation

\section{DISCLAIMER}

Any opinions, findings, and conclusions or recommendations expressed in this publication are those of the author(s) and do not necessarily reflect the views of the National Science Foundation, the participating agencies, Joint Oceanographic Institutions, Inc., Texas A\&M University, or Texas A\&M Research Foundation. 
ODP SCIENCE SERVICES

ODP SAfety Management Policies

Figure F1. Emergency assistance contact numbers and instructions.

A. AT ODP HEADQUARTERS:

\begin{tabular}{|l|l|l|}
\hline \multicolumn{1}{|c|}{ Position } & Phone \# & Pager \# \\
\hline Director & $979-845-8480$ & \\
\hline Deputy Director & $979-845-9297$ & \\
\hline Manager of Science Services & $979-862-2283$ & \\
\hline Supervisor of Technical Support & $979-845-6716$ & \\
\hline Manager of Drilling Services & $979-845-2024$ & \\
\hline $\begin{array}{l}\text { Materials Services Team - } \\
\text { Supervisor }\end{array}$ & $979-845-2113$ & \\
\hline Manager of Information Services & $979-845-9324$ & \\
\hline $\begin{array}{l}\text { Network and Admin. Services - } \\
\text { Supervisor }\end{array}$ & $979-845-9298$ & $979-228-0022$ \\
\hline Administrator (TAMRF) & $979-845-3068$ & \\
\hline Human Resources - Supervisor & $979-845-9288$ & \\
\hline
\end{tabular}

\section{B. ONBOARD THE JOIDES RESOLUTION:}

In Case of Fire use Emergency Fire Alarms located on each deck.

For Medical Emergency, call the Ship's Hospital at 200.

For all other emergencies, contact the Bridge first at 126.

\begin{tabular}{|l|l|}
\hline Dial & \multicolumn{1}{|c|}{ Contact } \\
\hline 126 & Bridge \\
\hline 200 & Ship's Hospital \\
\hline 122 & TSF Drilling Superintendent's Office \\
\hline 115 & ODP Drilling Superintendent's Office \\
\hline 114 & Laboratory Officer's Office \\
\hline 50 & Paging/Public Announcement System \\
\hline
\end{tabular}


Figure AF1. Texas Department of Health Notice to Employees summarizing the Texas Hazard Communication Act.

\section{NOTICE TO EMPLOYEES}

The Texas Hazard Communication Act (revised 1993), codified as Chapter 502 of the Texas Health and Safety Code, requires public employers to provide employees with specific information on the hazards of chemicals to which employees may be exposed in the workplace. As required by law, your employer must provide you with certain information and training. A brief summary of the law follows.

\section{HAZARDOUS CHEMICALS}

Hazardous chemicals are any products or materials that present any physical or health hazards when used, unless they are exempted under the law. Some examples of more commonly used hazardous chemicals are fuels, cleaning products, solvents, many types of oils, compressed gases, many types of paints, pesticides, herbicides, refrigerants, laboratory chemicals, cement, welding rods, etc.

\section{WORKPLACE CHEMICAL LIST}

Employers must develop a list of hazardous chemicals used or stored in the workplace in excess of 55 gallons or 500 pounds. This list shall be updated by the employer as necessary, but at least annually, and be made readily available for employees and their representatives on request.

\section{EMPLOYEE EDUCATION PROGRAM}

Employers shall provide training to newly assigned employees before the employees work in a work area containing a hazardous chemical. Covered employees shall receive training from the employer on the hazards of the chemicals and on measures they can take to protect themselves from those hazards. This training shall be repeated as needed, but at least whenever new hazards are introduced into the workplace or new information is received on the chemicals which are already present.

\section{MATERIAL SAFETY DATA SHEETS}

Employees who may be exposed to hazardous chemicals shall be informed of the exposure by the employer and shall have ready access to the most current material safety data sheets (MSDSs), which detail physical and health hazards and other pertinent information on those chemicals.

LABELS

Employees shall not be required to work with hazardous chemicals from unlabeled containers, except portable containers for immediate use, the contents of which are known to the user.

EMPLOYEE RIGHTS

Employees have rights to:

- access copies of MSDSs

- information on their chemical exposures

- receive training on chemical hazards

- receive appropriate protective equipment

- file complaints, assist inspectors, or testify against their employer

Employees may not be discharged or discriminated against in any manner for the exercise of any rights provided by this Act. A waiver of employee rights is void; an employer's request for such a waiver is a violation of the Act. Employees may file complaints with the Texas Department of Health at the toll free number provided below.

\section{EMPLOYERS MAY BE SUBJECT TO ADMINISTRATIVE PENALTIES AND CIVIL OR CRIMINAL FINES RANGING FROM \$50 TO $\$ 100,000$ FOR EACH VIOLATION OF THIS ACT. Further information may be obtained from: \\ Texas Department of Health Toxic Substances Control Division Hazard Communication Branch 1100 West 49th Street Austin, Texas 78756

\author{
$1-800-452-2791$ \\ (512) 834-6603 \\ Fax: (512) 834-6644
}

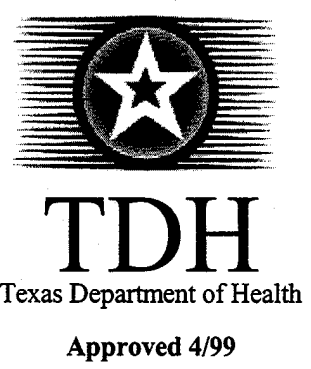


ODP SCIENCE SERVICES

ODP SAfety Management Policies

Table AT1. List of controlled items including precursor chemicals and related laboratory apparatus and glassware.

\begin{tabular}{ll}
\multicolumn{1}{c}{ Precursor chemicals } & \\
\hline Methylamine & Condensers \\
Ethylamine & Distilling apparatus \\
D-Lysergic acid & Vacuum dryers \\
Ergotamine tartrate & Three-necked flasks, two-necked flasks, single-necked flasks \\
Diethyl malonate & Distilling flasks \\
Malonic acid & Tableting machines \\
Ethyl malonate & Encapsulating machines \\
Barbituric acid & Filter funnels, Buchner funnels, and separatory funnels \\
Piperidine & Flasks: Erlenmeyer, two-neck, single-neck, round-bottom, thermometer, and filtering \\
N-acetyl anthranilic acid & Soxhlet extractors \\
Pyrrolidine & Transformers \\
Phenylacetic acid & Flask heaters \\
Anthranilic acid & Heating mantles \\
Ephedrine & Adapter tubes \\
Pseudoephedrine & \\
Norpseudoephedrine & \\
Phenylpropanolamine & \\
Controlled substance analog* & \\
\hline
\end{tabular}

Notes: * a substance that is substantially similar in chemical structure to that of a controlled substance or has central nervous system activity that is substantially similar to or greater than that of a controlled substance. The MOU does not establish any minimum quantities of precursor chemicals nor size of glassware or equipment. Prescription and nonprescription medicinal formulations are exempted. 